\title{
The use of Amplatzer devices in the percutaneous treatment of congenital heart defects in children and adults based
} on own experience

\author{
Jacek Białkowski, Małgorzata Szkutnik \\ Congenital Heart Defects and Paediatric Cardiology Department, Medical University of Silesia in Katowice, Silesian Centre for Heart Diseases, Zabrze, Poland
}

\author{
Correspondence to: \\ Prof. Jacek Białkowski, MD, \\ $\mathrm{PhD}$, \\ Congenital Heart Defects \\ and Paediatric Cardiology \\ Department, \\ Medical University of Silesia \\ in Katowice, \\ Silesian Centre for Heart \\ Diseases, \\ M Curie-Sklodowskiej 9 \\ 41-800 Zabrze, Poland, \\ phone: +48 606488 475, \\ e-mail: jabi_med@poczta. \\ onet.pl \\ Copyright by the Author(s), \\ 2021 \\ Kardiol Pol. 2021 \\ 79 (10): 1130-1132; \\ DOI: 10.33963/KP.a2021.0092 \\ Received: June 28, 2021 \\ Revision accepted: August \\ 15, 2021 \\ Published online: August \\ 17, 2021
}

\section{INTRODUCTION}

Amplatzer devices (AD) introduced to the clinical practice in the world in 1997 (first presentation) were a major breakthrough in congenital heart defects transcatheter treatment (TT). In 2021 our Department is celebrating the $24^{\text {th }}$ anniversary of implementing/using this method. The first author (JB) managed the Clinic from 1998 till now, and prof. M Szkutnik was the head of our catheterization laboratory until 2017 (now it is led by Dr R. Fiszer, MD, PhD).

\section{METHODS}

We presented here our 15 most important scientific papers on $A D$ application in the percutaneous closure of: (1) atrial septal defect (ASD); (2) patent ductus arteriosus (PDA); (3) postinfarction ventricular septal defect (PIVSD); and (4) vascular malformation. The total number of citations of this articles according to Web of Science was 317.

\section{RESULTS AND DISCUSSION}

\section{Atrial septal defect}

We performed 1847 procedures of ASD transcatheter closure at our Institute in the years 1997-2021 according to the guidance of the Association of Cardiovascular Interventions and the Grown-Up Congenital Heart Disease Section of the Polish Cardiac Society [1] (Figure 1). We published our preliminary data on the efficacy of TT of ASD in 2004 [2]. The article was recognized by the Spanish Society of Cardiology as the best publication of the year on pediatric cardiology. We demonstrated that ASD closure with Amplatzer atrial septal occluders (ASO) is safer than surgical treatment and leads to fewer complications [3]. Also, data on the better outcomes of transcatheter vs surgical ASD closure in regard to heart rate variability (HRV) parameters were documented. The experience in the closure of double ASDs with a single ASO was also presented [4]. We have concluded that double ASDs, which are very close to each other, can be occluded with one device. If the distance between both defects exceeds $7 \mathrm{~mm}$ (the difference in radius of the device and its waist is $7 \mathrm{~mm}$ ), the device should be slightly oversized. A small residual shunt is observed in those patients after the procedure, however, it usually disappears for up to a year. This phenomenon is the result of a slow and constant expansion of the device to its primary shape or the endothelialization (which takes approximately 6 months), or both.

The article related to adult patients underlined very good results of ASD closure also among 150 patients $>60$ years old and was most frequently cited [5]. Small children are another interesting group of patients. According to many textbooks, ASD should be closed at the age of 5-6 years. In 2018, we presented our experiences of successful ASD closure in 156 children aged $<3$ years old [6].

The issue of occurrence of arrhythmias and conduction abnormalities after ASD closure was discussed in the article published in 2008 [7]. Tachyarrhythmia was observed in $1.3 \%$ of patients up to 3 months after ASD closure $(n=9 / 738)$ : 8 patients had atrial fibrillation and 1 supraventricular tachycardia. All were successfully treated with antiarrhythmic drugs or cardioversion. The endothelialization process was suspected to be the major reason of tachyarrhythmias. Moreover, a complete 


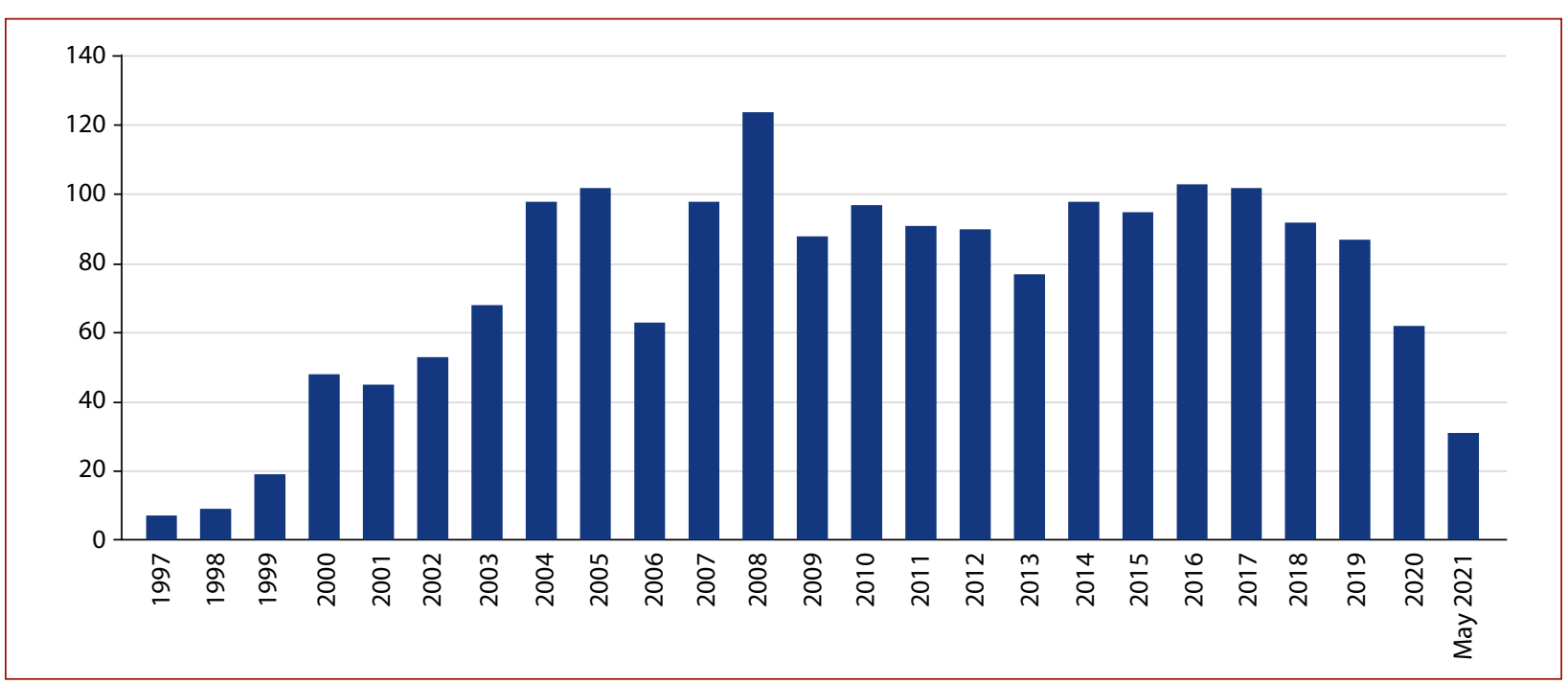

Figure 1. The number of procedures of transcatheter closure of atrial septal defect per year in Silesian Center for Heart Diseases in Zabrze (Poland) in the years 1997-2021

atrioventricular block occurred after 4.3 and 1.5 years, in two children with relatively small defects (at the age of 15 and 16, respectively), and both needed pacemaker implantation. This strongly underlines the necessity of constant follow-up of those patients. The delayed/incomplete process of endothelialization (or even absence of endothelialisation) is a rare finding after ASD closure with ASO, which was documented in our 20 years old patient with meningitis and infective endocarditis, which occurred two years after ASD closure [8].

\section{Patent ductus arteriosus}

We have performed over 1000 procedures of PDA transcatheter closure from 1993 to 2021, with different devices -558 with nitinol wire occluders [9]. Amplatzer Duct Occluder (ADO) type II Additional Sizes (ADOIIAS) originally was designed for small children. It should be highlited that it introduced in our team by Professor M. Szkutnik also in adult patients. ADOIIAS replaced coils to close small to medium PDAs in daily practice in our Clinic because of its high effectiveness and lack of complications [10]. Our three training trips to La Paz in Bolivia, which is situated at the level of 3600 meters above sea level, resulted in an interesting finding that PDAs at such high altitudes are considerably larger and that the ADOI is especially useful in those patients. The next step was to compare PDAs' characteristics between inhabitants of high-altitude cities (Mexico City, Guatemala City, La Paz, Bolivia) and low-altitude cities (Madrid, Spain; Zabrze, Poland). Patients from the last two cities had lower pulmonary artery pressures and smaller PDAs diameter vs. high-altitude inhabitants, which may have resulted from the higher partial pressure of oxygen [11]. This work was completed under the patronage of the Latin Pediatric Cardiology Society and carried out with this Society by the Interventional Cardiology Working Group (of which JB was the chairman in the years 2008-2012).

\section{Postinfarction ventricular septal defect}

PIVSD closure is a challenging problem in both the percutaneous and surgical approach. In the publication from 2003, we highlighted the low success rate of transcatheter PVSD closure in the acute phase after infarct (up to 3 weeks) due to friability of necrotic tissues [12]. Moreover, we found the ASO especially useful in such defects as its short waist suits well in thin scar tissue. We are currently collecting the long-term follow-ups on 23 patient survivors of this intervention. The general recommendation is to close the PIVSD in the acute phase with a surgical approach (patients in the worst clinical condition), and with TT in both subacute and chronic phases. Likewise, PIVSDs after surgery and with recanalization (not so rare) are also suitable for device closure.

\section{Vascular malformations}

In cooperation with colleagues from the National Institute of Cardiology in Mexico City, we described 5 patients with severe cyanosis, in whom we closed large pulmonary arteriovenous fistulas with the use of ADOI and with very good results [13].

In a 5-years-old child after Kawashima surgery (modified Fontan palliation) and with severe desaturation, we used the ASO to close a major intrahepatic venovenous malformation shunting to the atrium (over $2 \mathrm{~cm}$ in diameter). Both discs of the ASO device 'stented' the fistula and closed it completely [14]. Our experiences in percutaneous closure of ruptured sinuses of Valsalva aneurysm (RSVA) with various devices like ADOI and ASO were described in several papers reflecting various stages of our growing experience and longer patient observation. The last paper (published together with colleagues from the Amosov Institute in Kyiv, Ukraine) summarized results of RSVA closure in 23 patients, which is one of the largest reported cohorts [15]. We concluded that percutaneous closure of RSVA is (1) safe and effective, however, recanalizations are possible 
(in a different location); (2) it is also suitable for a second percutaneous attempt.

\section{Article information}

Conflict of interest: None declared.

Open access: This article is available in open access under Creative Common Attribution-Non-Commercial-No Derivatives 4.0 International (CC BY-NC-ND 4.0) license, allowing to download articles and share them with others as long as they credit the authors and the publisher, but without permission to change them in any way or use them commercially. For commercial use, please contact the journal office at kardiologiapolska@ptkardio.pl.

How to cite: Białkowski J, Szkutnik M. The use of Amplatzer devices in the percutaneous treatment of congenital heart defects in children and adults based on own experience. Kardiol Pol. 2021; 79(10): 1130-1132, doi: 10.33963/KP.a2021.0092.

\section{REFERENCES}

1. Grygier M, Sabiniewicz R, Smolka G, et al. Percutaneous closure of atrial septal defect: a consensus document of the joint group of experts from the Association of Cardiovascular Interventions and the Grown-Up Congenital Heart Disease Section of the Polish Cardiac Society. Kardiol Pol. 2020; 78(10): 1066-1083, doi: 10.33963/KP.15629, indexed in Pubmed: 33016689.

2. Bialkowski J, Kusa J, Szkutnik M, et al. Percutaneous catheter closure of atrial septal defect. Short-term and mid-term results [in Spanish] Rev Esp Cardiol. 2003; 56(4): 383-388, doi: 10.1016/s0300-8932(03)76882-1.

3. Bialkowski J, Karwot B, Szkutnik M, et al. Closure of atrial septal defects in children: surgery versus Amplatzer device implantation. Tex Heart Inst J. 2004; 31(3): 220-223, indexed in Pubmed: 15562840.

4. Szkutnik M, Masura J, Bialkowski J, et al. Transcatheter closure of double atrial septal defects with a single Amplatzer device. Catheter Cardiovasc Interv. 2004; 61(2): 237-241, doi: 10.1002/ccd.10753, indexed in Pubmed: 14755820.

5. Majunke N, Bialkowski J, Wilson N, et al. Closure of atrial septal defect with the Amplatzer septal occluder in adults. Am J Cardiol. 2009; 103(4): 550554, doi: 10.1016/j.amjcard.2008.10.018, indexed in Pubmed: 19195519.
6. Knop MT, Białkowski J, Szkutnik M, et al. Transcatheter closure of atrial septal defects type 2 in children under three years of age. Kardiol Pol. 2018; 76(8): 1257-1262, doi: 10.5603/KP.a2018.0113, indexed in Pubmed: 29862489.

7. Szkutnik M, Lenarczyk A, Kusa J, et al. Symptomatic tachy- and bradyarrhythmias after transcatheter closure of interatrial communications with Amplatzer devices. Cardiol J. 2008; 15(6): 510-516, indexed in Pubmed: 19039754.

8. Białkowski J, Pawlak S, Banaszak P. Incomplete endothelialisation of an Amplatzer Septal Occluder device followed by meningitis and late acute bacterial endocarditis. Cardiol Young. 2016; 26(4): 808-810, doi: 10.1017/S1047951115002383, indexed in Pubmed: 26707128.

9. Gałeczka M, Szkutnik M, Białkowski J, et al. Transcatheter patent ductus arteriosus closure: what have we learned after over 25 years? A single-center experience with 1036 patients. Kardiol Pol. 2021; 79(3): 287-293, doi: 10.33963/KP.15812, indexed in Pubmed: 33599452.

10. Fiszer R, Chojnicki M, SzkutnikM, et al. Are the AMPLATZER Duct Occluder II Additional Sizes devices dedicated only for smaller children? Eurolntervention. 2017; 12(17): 2100-2103, doi: 10.4244/EIJ-D-15-00238, indexed in Pubmed: 27867138.

11. Białkowski J, Głowacki J, Zabal C, et al. Patent ductus arteriosus at low and high altitudes: anatomical and haemodynamic features and their implications for transcatheter closure. Kardiol Pol. 2011; 69(5): 431-436, indexed in Pubmed: 21594824.

12. Szkutnik M., Białkowski J. Postinfarction ventricular septal defect closure with Amplatzer occluders. European Journal of Cardio-Thoracic Surgery. 2003; 23(3): 323-327, doi: 10.1016/s1010-7940(02)00812-6.

13. Bialkowski J,Zabal C, Szkutnik M, et al. Percutaneous interventional closure of large pulmonary arteriovenous fistulas with the amplatzer duct occluder. Am J Cardiol. 2005; 96(1): 127-129, doi: 10.1016/j.amjcard.2005.03.033, indexed in Pubmed: 15979450.

14. Szkutnik M, Bialkowski J, KnapikP. Major intrahepatic veno-venous fistula after modified Fontan operation treated by transcatheter implantation of amplatzer septal occluder. Cardiol Young. 2001; 11(3): 357-360, doi: 10.1017/s1047951101000415, indexed in Pubmed: 11388633.

15. Galeczka M, Glowacki J, Yashchuk N, et al. Medium- and long-term follow-up of transcatheter closure of ruptured sinus of Valsalva aneurysm in Central Europe population. J Cardiol. 2019; 74(4):381-387, doi: 10.1016/j. jjcc.2019.03.012, indexed in Pubmed: 31023567. 